\title{
Somatic embryogenesis and plant regeneration of cassava (Manihot esculenta Crantz) landraces from Cameroon
}

\author{
Kone Mongomake ${ }^{1,2}$, Oumar Doungous ${ }^{2,3}$, Behnam Khatabi ${ }^{1}$ and Vincent N. Fondong ${ }^{1 *}$
}

\begin{abstract}
A procedure to regenerate cassava (Manihot esculenta Crantz) cultivars from Cameroon via somatic embryogenesis (SE) was developed. Shoot apical meristems and immature leaf lobes were used as explants on Murashige and Skoog (MS) basal medium containing 33 or $50 \mu \mathrm{M}$ of the auxins Picloram (Pic), 2,4-Dichlorophenoxyacetic acid (2,4-D), Dicamba (Dic), and $\alpha$-Naphthalene acetic acid. Cultivar performance was assessed using SE and number of somatic embryos produced. Overall, the frequency of primary somatic embryogenesis (PSE) and the mean number of somatic embryos produced varied considerably with genotype, type of auxin and concentration tested. For example, cultivar (cv.) Ngan Mbada showed the best performance on MS medium supplemented with $50 \mu \mathrm{M}$ Pic with a SE frequency of $40 \%$ and an average number of somatic embryos of 90 . The second best performance was recorded in cv. Local Red on MS medium supplemented with $33 \mu \mathrm{M}$ 2,4-D, where the SE frequency was $40 \%$ and an average number of somatic embryos of 60.5. Cultivar Ekona Red recorded the best performance on medium supplemented with $50 \mu \mathrm{M}$ Pic showing a SE frequency of $47 \%$ and an average number of somatic embryos of 45 . We further examined secondary and cyclic somatic embryogenesis (SSE, CSE) and both were also observed to vary with genotype, however, both exhibited significantly higher frequencies of SE compared with PSE. SE started to decline at the fourth cycle of embryogenesis. Examination of organogenesis showed that shoot bud induction from green cotyledons varied across cultivars and benzylaminopurine was shown to outperform Thidiazuron in the ability to induce organogenesis. Furthermore, the frequencies of bud induction were identical under light and dark conditions. Finally, regenerated plants grew easily in the greenhouse with 90-100 \% survival rate and did not display detectable variation in morphology.
\end{abstract}

Keywords: Cassava, Somatic embryogenesis, Organogenesis, Plant growth regulators

\section{Background}

Cassava (Manihot esculenta Crantz) is a staple food to nearly a billion people in about 105 countries, providing as much as a third of daily calorie intake (FAO 2008a, b). World production was estimated at 250 million tons in 2011 (FAO 2012). In Africa, the continent with the largest production (53\% of world production), the crop plays an important role as famine-reserve crop, rural staple food, cash crop for both rural and urban households and, to a lesser extent, raw material for feed and chemical industries (Nweke et al. 2002). Because of its resilience and

\footnotetext{
*Correspondence: vfondong@desu.edu

${ }^{1}$ Department of Biological Sciences, Delaware State University,

Dover, DE 19901, USA

Full list of author information is available at the end of the article
}

capacity to grow on marginal lands, it is predicted that the importance of cassava cultivation in farming systems affected by climate change will increase in the future (Lobell et al. 2008). Furthermore, cassava starch exhibits high purity, solubility, low tendency to retrograde compared with other starches such as potato, rice and corn; this makes cassava a promising source for biofuel production (Zamora et al. 2010).

Despite its potentials for achieving food security and economic growth, biotic and abiotic constraints such as diseases, pests, weeds, and drought are limiting cassava production (Barceloux 2009; Bull et al. 2011). In addition to these constraints, production has several other constraints, including toxic cyanogenic compounds, very low protein content (1-2\% dried weight) and short fresh

\section{贷 Springer}


tissue shelf life of 1-3 days (Westby 2002). To improve the crop, therefore, important traits have been introgressed through traditional breeding, leading to major improvements in resistance to bacterial blight and viruses (Okogbenin et al. 2007). Furthermore, advances have been made in improving protein content (Chávez et al. 2005) and starch quality (Ceballos et al. 2007) through breeding. However, traditional breeding techniques face several limitations, notably, high heterozygosity, allopolyploidy, low fertility, unsynchronized flowering and limited knowledge of inheritance traits that have agronomic importance (Nassar and Ortiz 2010). Thus, production of improved plant lines by conventional breeding is a long and tedious process (Ceballos et al. 2004; Rudi et al. 2010). Therefore, cassava genetic transformation has emerged as a valuable alternative and complementary approach to improve the crop (Sayre et al. 2011; Liu et al. 2011).

An important prerequisite to developing a genetic transformation system is the availability of morphogenic culture that can easily be used in gene transfer techniques (Taylor et al. 2004). In cassava, the most efficient procedure to producing morphogenic culture is through somatic embryogenesis, which has become an integral component of genetic transformation systems in cassava (Osorio et al. 2012). Regeneration studies have shown that the frequency and efficiency of somatic embryogenesis are genotypedependent, and not all cassava cultivars are amenable to somatic embryogenesis, regeneration and/or transformation (Hankoua et al. 2005; Atehnkeng et al. 2006). This is yet an additional challenge to cassava improvement efforts. It therefore becomes necessary to optimize production of embryogenic structures for each cassava cultivar; yet, much of the research on cassava regeneration and transformation is currently largely devoted to varieties from South America (Taylor et al. 1993; Konan et al. 1994) even though much of the production is in Africa. Furthermore, previous reports showed that cassava cultivars from Africa respond differently in culture compared with South American varieties (Ihemere 2003). This study is aimed at investigating the ability of cassava genotypes from Cameroon to induce somatic embryos and regenerate plants via direct shoot regeneration from somatic cotyledons of maturing embryos. Results show that these Cameroonian cultivars are amenable to regeneration, even though the efficiency varied considerably with cultivar, auxin type and concentration. These results expand the range of African cassava cultivars that can be engineered using recombinant DNA technologies.

\section{Results}

Effect of plant growth regulators on induction of primary somatic embryogenesis

In this study, seven cassava cultivars from Cameroon were tested for their ability to induce primary somatic embryos on MS basal medium containing two concentrations (33 and $50 \mu \mathrm{M})$ of 2,4-D, Pic, NAA and Dic. The apical immature meristem leaf lobe explants (Fig. 1A) developed into a swollen callus mass on callus induction medium (CIM) within 5 days. From 3 to 4 weeks of culture, a compact non-embryogenic white callus (Fig. 1B) and translucent gelatinous callus with proembryogenic masses (Fig. 1C) were observed in all cultivars. These proembryogenic masses produced globular somatic embryos (Fig. 1D), which developed through the characteristic somatic embryogenesis stages of heart shape, torpedo and cotyledonary (Fig. 1E-H).

The potential of somatic embryogenesis, as indicated by the frequency of somatic embryo production, and the number of somatic embryos per explant, was assessed in each cultivar (Table 1). Results showed that both parameters varied widely across cultivar, auxin type and concentration. No primary somatic embryos were induced in medium containing $50 \mu \mathrm{M}$ NAA and Dic, respectively (Table 1). Generally, the callus induced on NAA medium was soft and primary somatic embryos were not formed, instead, all explants formed abundant adventitious roots. Three cultivars produced no somatic embryos on medium supplemented with $33 \mu \mathrm{M}$ Dic, while the other cultivars recorded a low frequency embryogenesis and few embryos were produced. The highest frequencies and number of somatic embryos per explant were observed in cv. Ngan Mbada (40.00\%; 90.00) on $50 \mu \mathrm{M}$ Pic, followed by Local Red (40.00 \%; 60.50) on $33 \mu \mathrm{M} 2,4-\mathrm{D}$, and Ekona Red $(46.67 \%$; 44.83) on $50 \mu \mathrm{M}$ Pic (Table 1$)$.

The Pearson correlation coefficient was used to relate the frequency of somatic embryogenesis to average number of somatic embryos per explant. Except for cv. Local Red, a significant positive correlation was observed between both parameters, indicating that the higher the frequency of somatic embryogenesis the more somatic embryos are formed (Table 2).

\section{Analysis of primary and secondary somatic embryogenesis on medium supplemented with Pic, 2,4-D and NAA}

We compared primary and secondary somatic embryogenesis on medium supplemented with $50 \mu \mathrm{M}$ Pic and 2,4-D and NAA, since the concentration of $50 \mu \mathrm{M}$ was found to be better than $33 \mu \mathrm{M}$ in inducing embryo proliferation (Table 1). In this experiment, we used five cultivars (Sekelen, Ngan Mbada, Ekona White, Local Red, and Ekona Red). All five cultivars exhibited $100 \%$ secondary somatic embryogenesis (Fig. 2A). However, cultivars behaved differently in the number of somatic embryos produced per explant (Fig. 2B). For example, cvs. Ngan Mbada and Ekona Red produced significantly higher average numbers of primary somatic embryos than the number of secondary embryos while crs. Ekona 

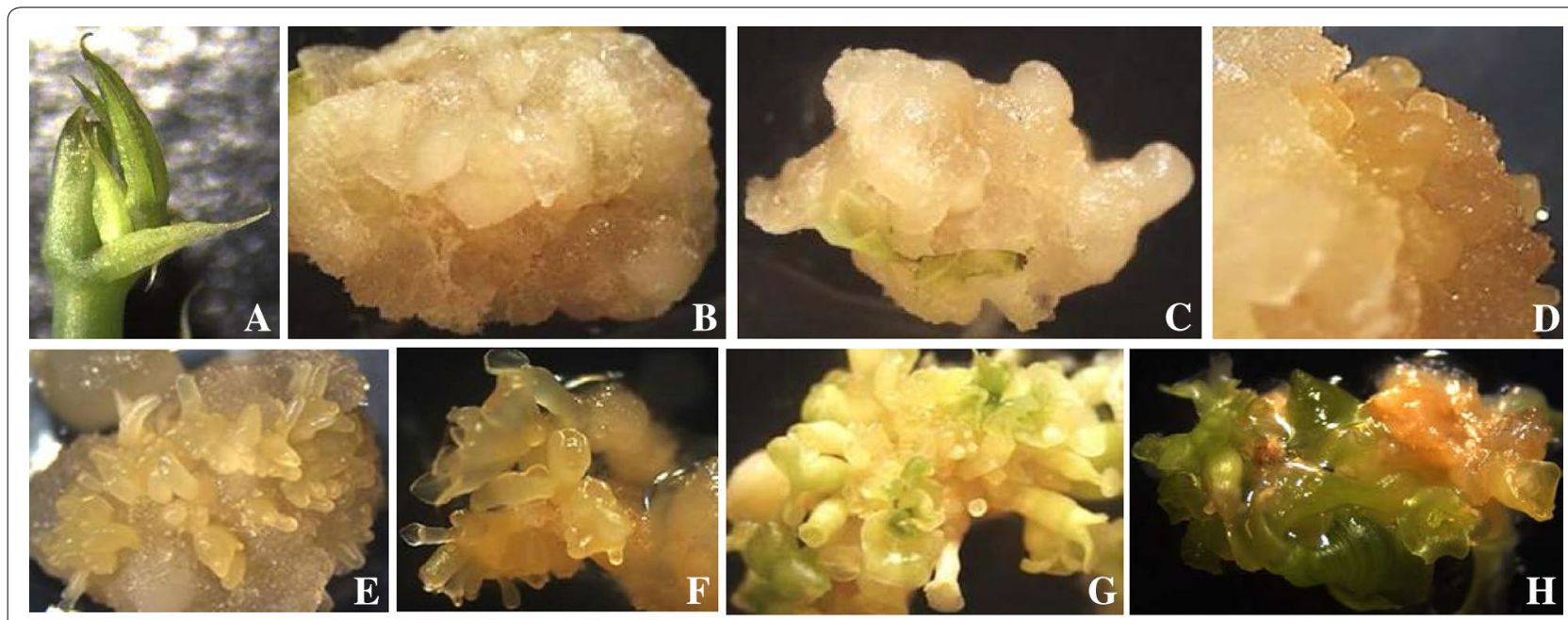

C

D
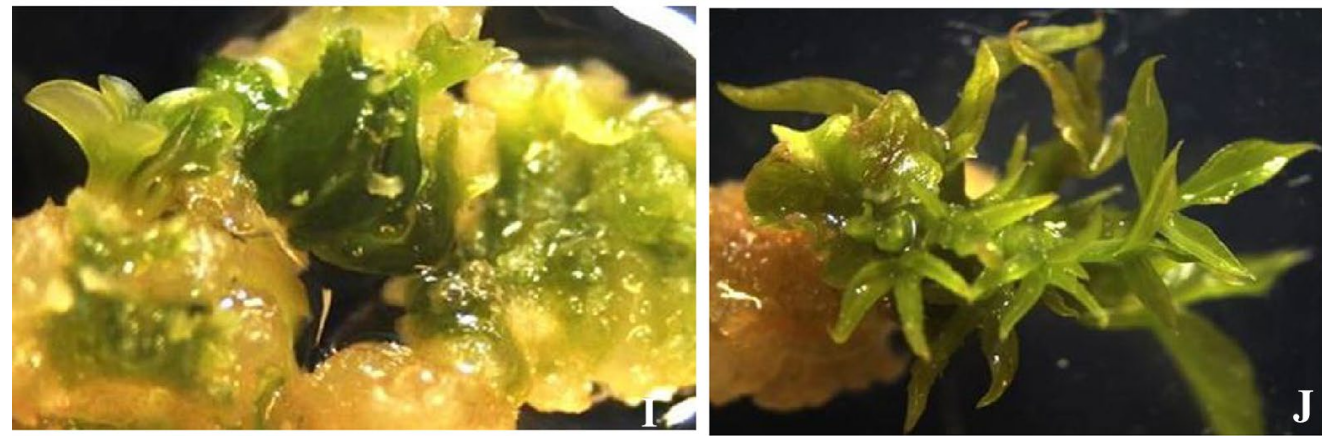

H
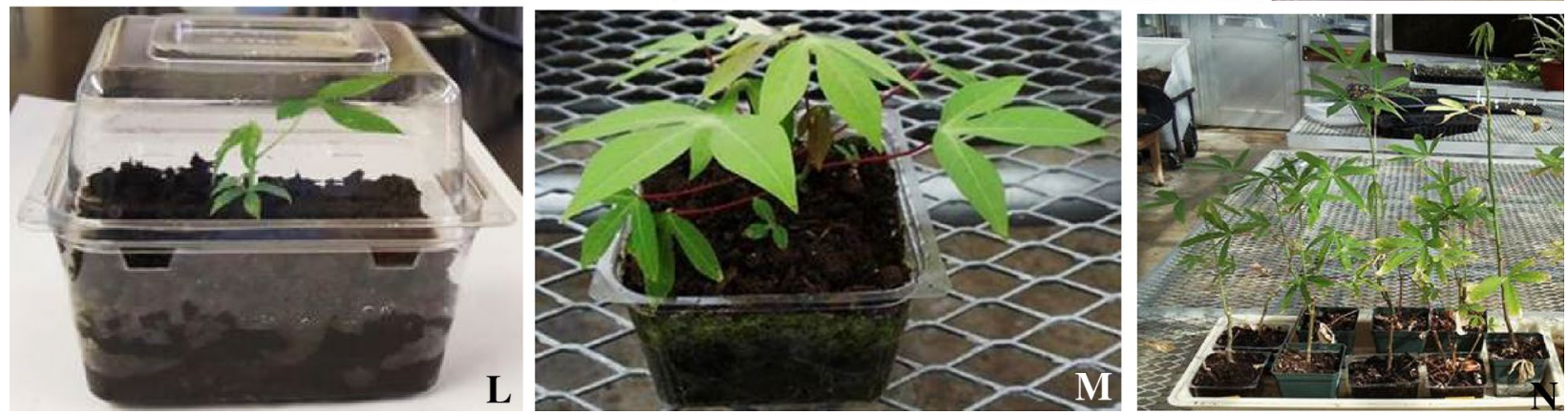

Fig. 1 Regeneration of cassava cultivars from Cameroon. Apical immature meristematic leaf lobe explants (A) induced compact non-embryogenic callus (B) and callus with proembryogenic masses (C). Clusters of organized embryogenic structures consisting of globular (D) heart and torpedo structures $(\mathbf{E})$, early cotyledonary stage $(\mathbf{F})$, asynchronous development of somatic embryos $(\mathbf{G})$ and green cotyledon $(\mathbf{H})$ were observed. Organogenic callus with buds (I) derived from green cotyledons developed clusters of shoot buds (J). Elongated shoot buds rooted and developed into whole plantlets $(\mathbf{K})$ in vitro. After transferring in boxes, hardened plantlets $(\mathbf{L})$ were acclimatized $(\mathbf{M})$ and they established in the greenhouse and grew into normal plants $(\mathbf{N})$

White and Ekona Red produced significantly higher average numbers of secondary somatic embryos. As for cvs. Sekelen, there was no statistical difference between the numbers of primary and secondary embryos (Fig. 2B).

The effects of the three auxins on embryo induction frequency, number of somatic embryos per explant, and time (days) to complete the process, were determined. All three auxins induced secondary somatic embryogenesis in all five cultivars with frequencies varying from 57 to
$100 \%$ (Table 3). The frequencies of somatic embryogenesis were similar in cvs. Ekona White and Local Red under all three auxins. Pic and, to a lesser extent, 2,4-D induced a significantly higher frequency of somatic embryos than NAA in cvs. Sekelen, Ngan Mbada and Ekona Red. The lowest numbers of somatic embryos produced in all five cultivars were observed on medium supplemented with NAA (Table 3). The average number of days to complete somatic embryogenesis was significantly lower on NAA 
Table 1 Effect of plant growth regulators on somatic embryogenesis derived from immature shoot apical meristems of cassava cultivars from Cameroon

\begin{tabular}{|c|c|c|c|}
\hline Plant growth regulators & Varieties & Frequency (\%) of SE & Number of SE/explant \\
\hline \multirow[t]{7}{*}{ Picloram $33 \mu \mathrm{M}$} & Sekelen & $20.00 \pm 5.77 \mathrm{e}$ & $08.00 \pm 1.15 \mathrm{jk}$ \\
\hline & Ya Oroup & $0.00 \pm 0.00$ & $0.00 \pm 0.00$ \\
\hline & Ngan Mbada & $20.00 \pm 5.77 \mathrm{e}$ & $59.33 \pm 11.40 c$ \\
\hline & Ekona White & $0.00 \pm 0.00$ & $0.00 \pm 0.00$ \\
\hline & Local Red & $60.00 \pm 11.54 a b$ & $08.00 \pm 0.57 \mathrm{jk}$ \\
\hline & Ekona Red & $0.00 \pm 0.00$ & $0.00 \pm 0.00$ \\
\hline & Local Ama & $40.00 \pm 11.54 \mathrm{cde}$ & $14.00 \pm 3.21 \mathrm{ij}$ \\
\hline \multirow[t]{7}{*}{ 2,4-D $33 \mu \mathrm{M}$} & Sekelen & $40.00 \pm 11.54$ cde & $21 \pm 0.57 \mathrm{ghi}$ \\
\hline & Ya Oroup & $0.00 \pm 0.00$ & $0.00 \pm 0.00$ \\
\hline & Ngan Mbada & $0.00 \pm 0.00$ & $0.00 \pm 0.00$ \\
\hline & Ekona White & $0.00 \pm 0.00$ & $0.00 \pm 0.00$ \\
\hline & Red Local & $40.00 \pm 5.77$ cde & $60.50 \pm 3.50 c$ \\
\hline & Ekona Red & $40.00 \pm 11.54$ cde & $26.50 \pm 4.90 \mathrm{fg}$ \\
\hline & Local Ama & $40.00 \pm 5.77$ cde & $17.00 \pm 3.46 \mathrm{hi}$ \\
\hline \multirow[t]{7}{*}{ NAA $33 \mu \mathrm{M}$} & Sekelen & $0.00 \pm 0.00$ & $0.00 \pm 0.00$ \\
\hline & Ya Oroup & $0.00 \pm 0.00$ & $0.00 \pm 0.00$ \\
\hline & Ngan Mbada & $0.00 \pm 0.00$ & $0.00 \pm 0.00$ \\
\hline & Ekona White & $0.00 \pm 0.00$ & $0.00 \pm 0.00$ \\
\hline & Local Red & $0.00 \pm 0.00$ & $0.00 \pm 0.00$ \\
\hline & Ekona Red & $0.00 \pm 0.00$ & $0.00 \pm 0.00$ \\
\hline & Local Ama & $0.00 \pm 0.00$ & $0.00 \pm 0.00$ \\
\hline \multirow[t]{7}{*}{ Diccamba $33 \mu \mathrm{M}$} & Sekelen & $20.00 \pm 5.77 \mathrm{e}$ & $04.67 \pm 0.67 k$ \\
\hline & Ya Oroup & $20.00 \pm 11.54 \mathrm{e}$ & $04.67 \pm 2.40 \mathrm{k}$ \\
\hline & Ngan Mbada & $0.00 \pm 0.00$ & $0.00 \pm 0.00$ \\
\hline & Ekona White & $0.00 \pm 0.00$ & $0.00 \pm 0.00$ \\
\hline & Local Red & $20.00 \pm 11.54 \mathrm{e}$ & $04.00 \pm 2.08 k$ \\
\hline & Ekona Red & $0.00 \pm 0.00$ & $0.00 \pm 0.00$ \\
\hline & Local Ama & $20.00 \pm 5.77 e$ & $08.00 \pm 2.08 \mathrm{jk}$ \\
\hline \multirow[t]{7}{*}{ Picloram $50 \mu \mathrm{M}$} & Sekelen & $80.00 \pm 11.54 \mathrm{a}$ & $44 \pm 5.56 \mathrm{e}$ \\
\hline & Ya Oroup & $0.00 \pm 0.00$ & $0.00 \pm 0.00$ \\
\hline & Ngan Mbada & $40.00 \pm 11.54$ cde & $90.00 \pm 21.96 a$ \\
\hline & Ekona White & $63.33 \pm 14.52 \mathrm{ab}$ & $32.00 \pm 5.19 f$ \\
\hline & Local Red & $60.00 \pm 20.00 \mathrm{ab}$ & $15.50 \pm 3.32 \mathrm{ij}$ \\
\hline & Ekona Red & $46.67 \pm 17.63 \mathrm{bcd}$ & $44.83 \pm 21.22 \mathrm{e}$ \\
\hline & Local Ama & $40.00 \pm 11.54$ cde & $47.66 \pm 14.83 \mathrm{de}$ \\
\hline \multirow[t]{7}{*}{ 2,4-D $50 \mu \mathrm{M}$} & Sekelen & $40.00 \pm 11.54$ cde & $21.00 \pm 0.57 \mathrm{ghi}$ \\
\hline & Ya Oroup & $20.00 \pm 0.00 \mathrm{e}$ & $16.00 \pm 2.08 \mathrm{ij}$ \\
\hline & Ngan Mbada & $50.00 \pm 5.77 b c$ & $78.50 \pm 2.02 b$ \\
\hline & Ekona White & $20.00 \pm 0.00 \mathrm{e}$ & $34.00 \pm 3.46 \mathrm{f}$ \\
\hline & Local Red & $20.00 \pm 0.00 \mathrm{e}$ & $22.00 \pm 5.19 \mathrm{ghi}$ \\
\hline & Ekona Red & $20.00 \pm 0.00 \mathrm{e}$ & $54.00 \pm 9.23 \mathrm{~cd}$ \\
\hline & Local Ama & $0.00 \pm 0.00$ & $0.00 \pm 0.00$ \\
\hline \multirow[t]{7}{*}{ NAA $50 \mu \mathrm{M}$} & Sekelen & $0.00 \pm 0.00$ & $0.00 \pm 0.00$ \\
\hline & Ya Oroup & $0.00 \pm 0.00$ & $0.00 \pm 0.00$ \\
\hline & Ngan Mbada & $0.00 \pm 0.00$ & $0.00 \pm 0.00$ \\
\hline & Ekona White & $0.00 \pm 0.00$ & $0.00 \pm 0.00$ \\
\hline & Local Red & $0.00 \pm 0.00$ & $0.00 \pm 0.00$ \\
\hline & Ekona Red & $0.00 \pm 0.00$ & $0.00 \pm 0.00$ \\
\hline & Local Ama & $0.00 \pm 0.00$ & $0.00 \pm 0.00$ \\
\hline
\end{tabular}


Table 1 continued

\begin{tabular}{llll}
\hline Plant growth regulators & Varieties & Frequency (\%) of SE & Number of SE/explant \\
\hline Diccamba $50 \mu \mathrm{M}$ & Sekelen & $0.00 \pm 0.00$ \\
& Ya Oroup & $0.00 \pm 0.00$ \\
& Ngan Mbada & $0.00 \pm 0.00$ \\
& Ekona White & $0.00 \pm 0.00$ & $0.00 \pm 0.00$ \\
& Local Red & $0.00 \pm 0.00$ \\
$0.00 \pm 0.00$ & $0.00 \pm 0.00$ \\
0.00 & $0.00 \pm 0.00$ & 0.00
\end{tabular}

Within the same column, mean values followed by the same letter are not significantly different at $\alpha=5 \%$ (Newman-Keuls test)

\pm , standard deviation; SE, somatic embryos

Table 2 Correlations between frequency of somatic embryos induced and the average number of somatic embryos of cassava cultivars from Cameroon

\begin{tabular}{ll}
\hline Varieties & $\begin{array}{l}\text { Correlations } \\
\text { (\% SE-NB SE) }\end{array}$ \\
\hline Sekelen & $0.848^{*}$ \\
Ya Oroup & $0.621^{*}$ \\
Ngan Mbada & $0.958^{*}$ \\
Ekona White & $0.719^{*}$ \\
Local Red & $0.382 \mathrm{NS}$ \\
Ekona Red & $0.818^{*}$ \\
Local Ama & $0.782^{*}$ \\
\hline
\end{tabular}

NS non significant (bilateral test at $\alpha=5 \%$ )

* Significant

medium than on Pic or 2,4-D, both of which behaved similarly.

\section{Effect of embryo cycling on plant regeneration}

We investigated the effect of successive embryo cycling on induction of somatic embryos by determining the frequency and number of somatic embryos induced during the third and fourth cycles in the presence of Pic, 2,4-D and NAA. Results showed that on media supplemented with Pic and NAA, somatic embryo induction was observed to be $100 \%$ in both third and fourth cycles (Fig. 3A). In contrast, a lower frequency was observed in medium supplemented with 2,4-D in the fourth cycle. As for the effect of cycling on the number of embryos, the third cycle showed a significantly higher number than the fourth cycle (Fig. 3B).

\section{Effect of BAP and TDZ on organogenesis under light and dark conditions}

The effect of cytokinin BAP $(1 \mathrm{mg} / \mathrm{L})$ and cytokininlike growth regulator, TDZ $(0.022 \mathrm{mg} / \mathrm{L})$, on organ production from green cotyledon somatic embryos was investigated under light and dark conditions. Frequencies of callus and bud formation as well as number of buds produced per explant are presented in Table 4 . In medium supplemented with TDZ, no callus induction was observed under light or dark in all five cultivars. In medium supplemented with BAP, however, frequencies ranged from 81 to $100 \%$ with no significant differences in the frequency of callus production under light and dark conditions across all five cultivars assessed.

As for shoot regeneration, all five cultivars produced shoots from secondary and cyclic embryos (Fig. 1i). Overall, the frequencies of bud formation were similar under light and dark conditions with higher values recorded in medium supplemented with BAP (53.00-71.55 \%) than in medium containing TDZ (0.00-34.00\%) where the frequency of budding tended to be higher under dark (6.40$34.00 \%)$ than under light (0.00-20.00\%) (Table 4). As for the number of buds formed, medium supplemented with BAP performed better than TDZ supplemented medium (Table 4). Taken together, organogenesis was higher in cvs. Ekona Red (62.72 \%; 19.67 buds), Red Local (56.00 \%; 18.82 buds) and Sekelen (69.00 \%; 13.48 buds), while cv. Ngan Mbada recorded the lowest values (66.00\%; 8.30 buds) in medium supplemented with BAP.

\section{Rooting and acclimatization of regenerated plantlets}

Prior to transplanting to the greenhouse, lengths of shoots regenerated on maturation medium were measured; values ranged from 0.8 to $1.08 \mathrm{~cm}$ and showed no statistical differences (Fig. 4A). Shoots (Fig. 1J) of all cultivars developed roots efficiently on elongation medium supplemented with $0.4 \mathrm{mg} / \mathrm{L}$ BAP. We assessed the ability of regenerated plantlets to acclimatize and grow in the greenhouse by measuring the proportion of plantlets recovered as well as plantlet height. Cultivars Ngan Mbada and Ekona Red showed a significantly higher regeneration rate than cultivars Ekona White and Local Red (Fig. 4B). The regenerated plants were morphologically normal and grew rapidly (Fig. 1N) and after 6 weeks 

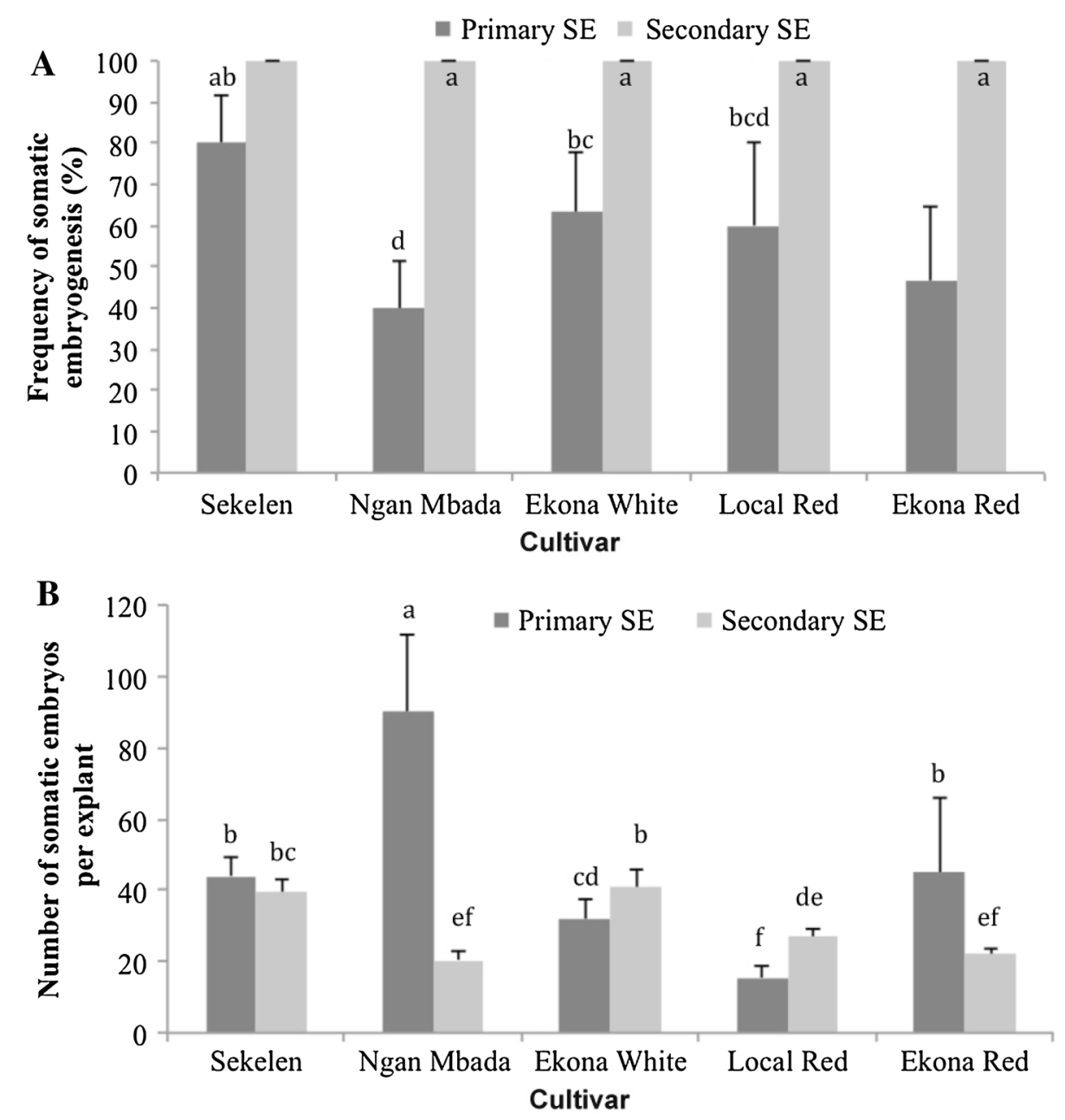

Fig. 2 Efficiency of primary and secondary somatic embryogenesis as indicated by frequency of induction $(\mathbf{A})$ and average number of somatic embryos per explant $(\mathbf{B})$. Values represent the mean \pm SD $(n=50)$. Different letters on error bars are significantly different at $\alpha=0.05$ (NewmanKeuls test)

under greenhouse conditions, plantlets height ranged from 18 to $27 \mathrm{~cm}$ (Fig. 4A).

\section{Discussion}

Despite its immense importance in the developing world, cassava has historically received less attention by researchers than have temperate crops (Olsen and Schaal 1999). Much of the genetic improvements of this crop have been through traditional breeding, which has resulted in the introgression into the cassava germplasm of bacterial and virus resistance (Hahn et al. 1980; Okogbenin et al. 2007) as well as other useful traits (Chávez et al. 2005; Ceballos et al. 2007; Morante et al. 2010; Rudi et al. 2010). Traditional breeding techniques face several limitations, notably the heterozygous nature of the crop, which renders it difficult to identify the true breeding value of parental lines. Furthermore, there is limited knowledge of inheritance traits that have agronomic importance (Ceballos et al. 2004; Olsen and Schaal 1999; Nassar and Ortiz 2010). These challenges, together with the fact that not all cultivated genotypes are amenable to breeding, not being able to produce flowers, make cassava improvement difficult. Thus, improvement through genetic engineering, which principally is carried out using Agrobacterium-mediated transformation of friable embryogenic callus (González et al. 1998; Zhang et al. 2001), has become a method of choice in cassava improvement.

Efficient Agrobacterium-mediated transformation of a recalcitrant crop as cassava depends on the ability to deliver intact DNA molecules into the genome of regenerable cells and to recover adult plants. Thus, production of somatic embryos, which are used as target tissue for insertion of T-DNA in the cassava genome, is a 
Table 3 Effect of auxins on secondary and cyclic somatic embryogenesis of five cassava cultivars from Cameroon

\begin{tabular}{llccc}
\hline Varieties & Auxin $\mathbf{( 5 0} \boldsymbol{\mu M})$ & $\begin{array}{c}\text { Frequency } \mathbf{( \% )} \\
\text { of } \mathbf{S E} \text { induction }\end{array}$ & $\begin{array}{c}\text { Average number } \\
\text { of SE per explant }\end{array}$ & $\begin{array}{l}\text { Average days to } \\
\text { complete the process }\end{array}$ \\
\hline Sekelen & Pic & $100.00 \pm 0.00 \mathrm{a}$ & $56.25 \pm 8.01 \mathrm{c}$ & $25.00 \pm 2.22 \mathrm{a}$ \\
& NAA & $60.00 \pm 0.00 \mathrm{~d}$ & $22.00 \pm 4.72 \mathrm{fg}$ & $11.00 \pm 1.1 \mathrm{~b}$ \\
Ngan Mbada & $2,4-\mathrm{D}$ & $73.33 \pm 6.67 \mathrm{bc}$ & $55.67 \pm 5.90 \mathrm{c}$ & $27.00 \pm 3.5 \mathrm{a}$ \\
& Pic & $96.67 \pm 3.33 \mathrm{a}$ & $37.20 \pm 1.17 \mathrm{e}$ & $26.00 \pm 3.7 \mathrm{a}$ \\
& NAA & $57.33 \pm 1.33 \mathrm{~d}$ & $11.33 \pm 0.33 \mathrm{~h}$ & $12.00 \pm 1.5 \mathrm{~b}$ \\
Ekona White & 2,4-D & $66.67 \pm 6.67 \mathrm{~cd}$ & $26.33 \pm 2.60 \mathrm{f}$ & $24.00 \pm 1.6 \mathrm{a}$ \\
& Pic & $100.00 \pm 0.00 \mathrm{a}$ & $92.33 \pm 7.88 \mathrm{a}$ & $23.00 \pm 2.3 \mathrm{a}$ \\
Local Red & NAA & $84.00 \pm 2.08 \mathrm{ab}$ & $14.67 \pm 2.72 \mathrm{gh}$ & $11.00 \pm 1.6 \mathrm{~b}$ \\
& 2,4-D & $84.00 \pm 2.08 \mathrm{ab}$ & $71.00 \pm 11.23 \mathrm{~b}$ & $22.00 \pm 1.8 \mathrm{a}$ \\
Ekona Red & Pic & $100.00 \pm 0.00 \mathrm{a}$ & $56.00 \pm 4.93 \mathrm{c}$ & $28.00 \pm 1.8 \mathrm{a}$ \\
& NAA & $100.00 \pm 0.00 \mathrm{a}$ & $15.58 \pm 1.52 \mathrm{~g}$ & $12.00 \pm 2.4 \mathrm{~b}$ \\
& 2,4-D & $100.00 \pm 0.00 \mathrm{a}$ & $49.33 \pm 8.11 \mathrm{~cd}$ & $29.00 \pm 0.8 \mathrm{a}$ \\
& Pic & $100.00 \pm 0.00 \mathrm{a}$ & $44.00 \pm 5.29 \mathrm{de}$ & $22.00 \pm 4.2 \mathrm{a}$ \\
\hline
\end{tabular}

Within the same column, mean values followed by the same letter are not significantly different at $\alpha=5 \%$ (Newman-Keuls test)

\pm , standard deviation; $\mathrm{SE}$, somatic embryogenesis
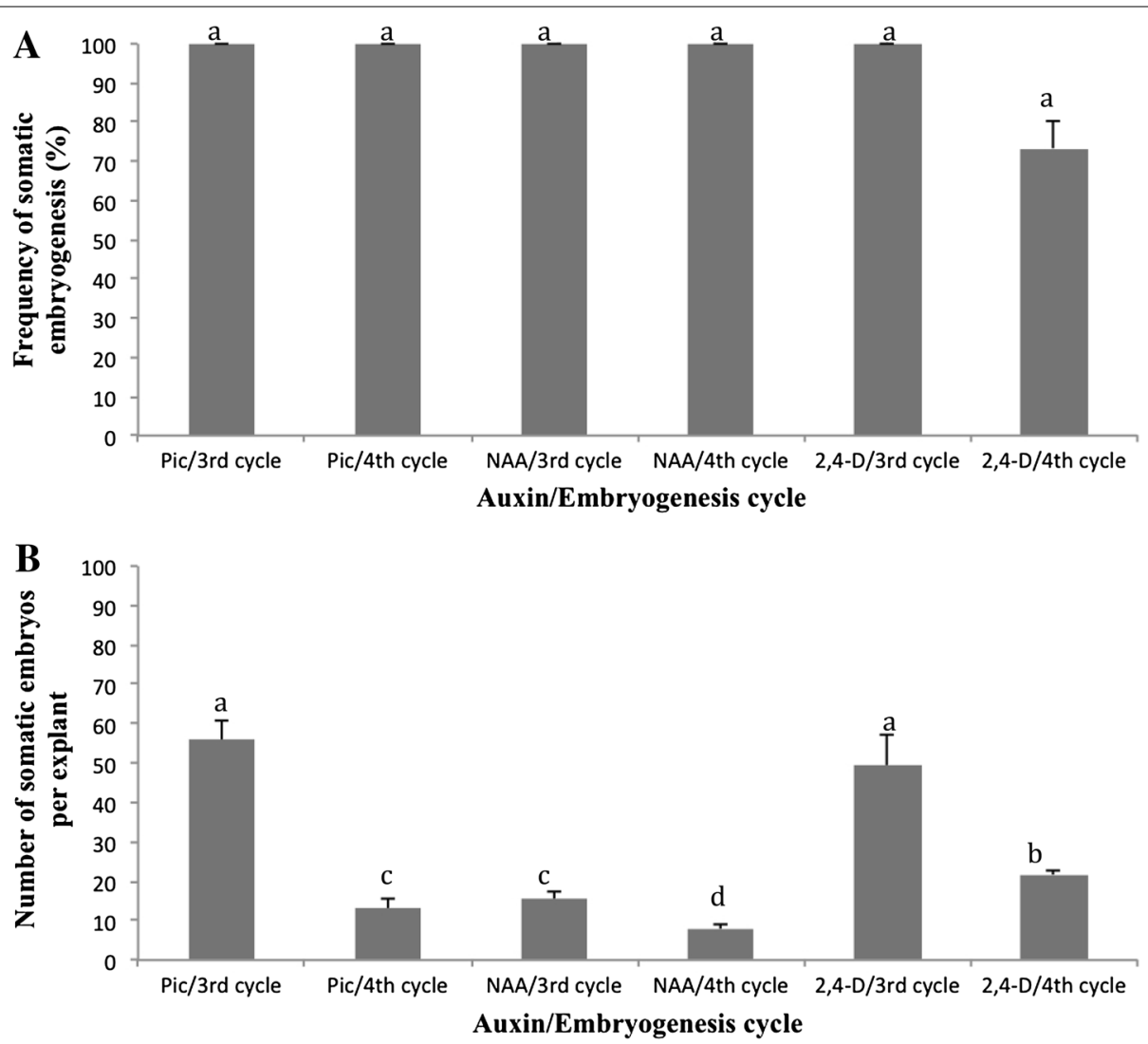

Fig. 3 Influence of the number of cycles on somatic embryogenesis on medium supplemented with auxins Pic, NAA and 2,4-D as indicated by frequency of induction $(\mathbf{A})$ and the average number of somatic embryos $(\mathbf{B})$ were recorded. Data represent the mean $\pm \operatorname{SD}(n=50)$. Different letters on error bars are significantly different at $\alpha=0.05$ (Newman-Keuls test) 
Table 4 Effect of cytokinins and photoperiod on callus and bud induction from green somatic embryos of five cassava cultivars from Cameroon

\begin{tabular}{|c|c|c|c|c|c|c|c|}
\hline \multirow[t]{2}{*}{ Var } & \multirow[t]{2}{*}{ Cyt } & \multicolumn{2}{|c|}{ Frequency (\%) of callus induction } & \multicolumn{2}{|c|}{ Frequency (\%) of bud induction } & \multicolumn{2}{|c|}{ Average number of buds per explant } \\
\hline & & Photoperiod & Dark & Photoperiod & Dark & Photoperiod & Dark \\
\hline \multirow[t]{2}{*}{ SK } & BAP & $91.00 \pm 3.71 \mathrm{a}$ & $90.00 \pm 3.33 a$ & $69.00 \pm 6.74 \mathrm{a}$ & $56.00 \pm 7.18 \mathrm{a}$ & $13.48 \pm 0.43 \mathrm{abcd}$ & $07.97 \pm 1.20 \mathrm{cdef}$ \\
\hline & TDZ & $0.00 \pm 0.00 b$ & $0.00 \pm .00 \mathrm{~b}$ & $12.00 \pm 3.26$ de & $16.00 \pm 5.81$ cde & $02.40 \pm 0.70 \mathrm{e}$ & $0.90 \pm 0.31 \mathrm{f}$ \\
\hline \multirow[t]{2}{*}{ NM } & BAP & $81.00 \pm 6.04 \mathrm{a}$ & $92.00 \pm 4.42 \mathrm{a}$ & $53.00 \pm 5.17 a b$ & $66.00 \pm 4.26 \mathrm{a}$ & $08.30 \pm 0.72 \mathrm{ce}$ & $06.90 \pm 0.30$ def \\
\hline & TDZ & $0.00 \pm 0.00 b$ & $0.00 \pm 0.00 b$ & $0.00 \pm .00 \mathrm{e}$ & $06.40 \pm 2.97 \mathrm{e}$ & $0.00 \pm .00 f$ & $0.80 \pm 0.29$ ef \\
\hline \multirow[t]{2}{*}{ EW } & BAP & $81.77 \pm 6.30 \mathrm{a}$ & $86.00 \pm 3.05 a$ & $71.55 \pm 9.59 \mathrm{a}$ & $54.30 \pm 7.38 a b$ & $11.30 \pm 0.74$ bcde & $06.48 \pm 0.86$ def \\
\hline & TDZ & $0.00 \pm 0.00 b$ & $0.00 \pm 0.00 b$ & $20.00 \pm 0.00$ cde & $28.00 \pm 7.42 \mathrm{~cd}$ & $5.00 \pm 0.00$ ef & $0.90 \pm 0.23$ ef \\
\hline \multirow[t]{2}{*}{$\mathrm{RL}$} & BAP & $100.00 \pm 0.00$ & $100.00 \pm 0.00$ & $56.00 \pm 6.53 \mathrm{a}$ & $54.00 \pm 5.81 \mathrm{ab}$ & $18.82 \pm 1.52 \mathrm{ab}$ & $06.30 \pm 0.65$ def \\
\hline & TDZ & $0.00 \pm 0.00 b$ & $06.00 \pm 3.05 b$ & $10.00 \pm 3.33 \mathrm{de}$ & $34.00 \pm 7.91 b c$ & $0.50 \pm 0.16 f$ & $02.45 \pm 0.72$ ef \\
\hline \multirow[t]{2}{*}{ ER } & BAP & $100.00 \pm 0.00$ & $100.00 \pm 0.00$ & $62.00 \pm 5.53 \mathrm{a}$ & $62.70 \pm 5.20 \mathrm{a}$ & $19.67 \pm 2.70 \mathrm{a}$ & $15.26 \pm 2.22 \mathrm{abc}$ \\
\hline & TDZ & $0.00 \pm 0.00 \mathrm{~b}$ & $0.00 \pm 0.00 b$ & $0.00 \pm .00 \mathrm{e}$ & $06.40 \pm 2.97 \mathrm{e}$ & $0.00 \pm .00 f$ & $0.80 \pm 0.29$ ef \\
\hline
\end{tabular}

Within the same column, mean values followed by the same letter are not significantly different at $\alpha=5 \%$ (Newman-Keuls test)

\pm , standard deviation; Var, varieties; Cyt, cytokinins

critical step in cassava transformation. In this study, we investigated the regeneration proficiency of cassava cultivars from Cameroon on media supplemented with Pic, Dic, NAA and 2,4-D. Visual assessment of culture using stereomicroscopy revealed the formation of somatic embryos exhibiting globular, heart shape, torpedo and cotyledonary stages on the same piece of callus tissue. This suggested that somatic embryogenesis is asynchronous, characterized by the presence of globular somatic embryos and embryos at more advanced stages of development on the same callus structure, similar to structures reported recently on cv. Cigana Preta, a Brazilian cassava cultivar (Vidal et al. 2014).

Addition of a strong auxin to the culture medium is known to efficiently induce in vitro somatic embryogenesis. Thus, 2,4-D was shown to be very efficient in inducing embryogenesis in Anthurium andraeanum (Pinheiro et al. 2013) and sweet potato [Ipomoea batatas (L.) Lam] (Magalhães et al. 2006). Here, we observed that all Cameroonian cassava cultivars were amenable to embryogenesis on media supplemented with Pic, 2,4-D and, to a lesser extent, Dic. In contrast, NAA failed to induce embryogenesis from leaf-lobe explants in all cultivars. These results were consistent with those of Sofiari et al. (1997), who assessed cultivars from Africa, South America and Asia. NAA tended to induce production of soft callus, which is not proficient in developing somatic embryos. Prolific induction of somatic embryos was obtained on media supplemented with 2,4-D and Pic. Both auxins have commonly been used in the induction of cassava somatic embryos ( $\mathrm{Li}$ et al. 1996; Taylor et al. 2001; Zhang and Puonti-Kaerlas 2005). In our hands, Pic and 2.4-D at a concentration of $50 \mu \mathrm{M}$ was more effective in inducing somatic embryos than $33 \mu \mathrm{M}$. Pic has constantly been shown to be more efficient in inducing embryo formation in African cassava cultivars ( $\mathrm{Ng}$ and Adeniyi 1994; Raemakers et al. 1993; Rossin and Rey 2011), South America (Feitosa et al. 2007), and Asia (Li et al. 1998; Saelim et al. 2006). We also showed that the frequency of somatic embryogenesis and the number of embryos produced per explant varied with cultivar and auxin, suggesting a genotype-auxin interaction effect as reported by others (Feitosa et al. 2007; Saelim et al. 2006; Rossin and Rey 2011).

Somatic embryogenesis has consistently been assessed using induction frequency (Hankoua et al. 2005; Szabados et al. 1987) or number of somatic embryos per explant (Danso and Ford-Lloyd 2002; Feitosa et al. 2007; Ibrahim et al. 2008). These studies, however, have not investigated the possibility of a correlation between frequency and number of embryos formed. We have shown here that a significant positive correlation exists between frequency and number of somatic embryos produced in six of the seven cultivars investigated. This indicates that for most cassava cultivars, there is a high efficiency of proembryogenic mass conversion to various developmental stages of somatic embryos. It is therefore likely that these proembryogenic masses originate from cells that have acquired the capacity to induce formation of somatic embryos.

Consistent with previous reports on other cultivars (Hankoua et al. 2005; Sofiari et al. 1997; Zhang et al. 2001), we found that secondary somatic embryogenesis was induced in all five Cameroonian cultivars assessed in this study. However, we found that the frequency and number of somatic embryos varied across cultivars. The frequency of secondary embryogenesis was $100 \%$ for all cultivars investigated, however, the number of embryos 

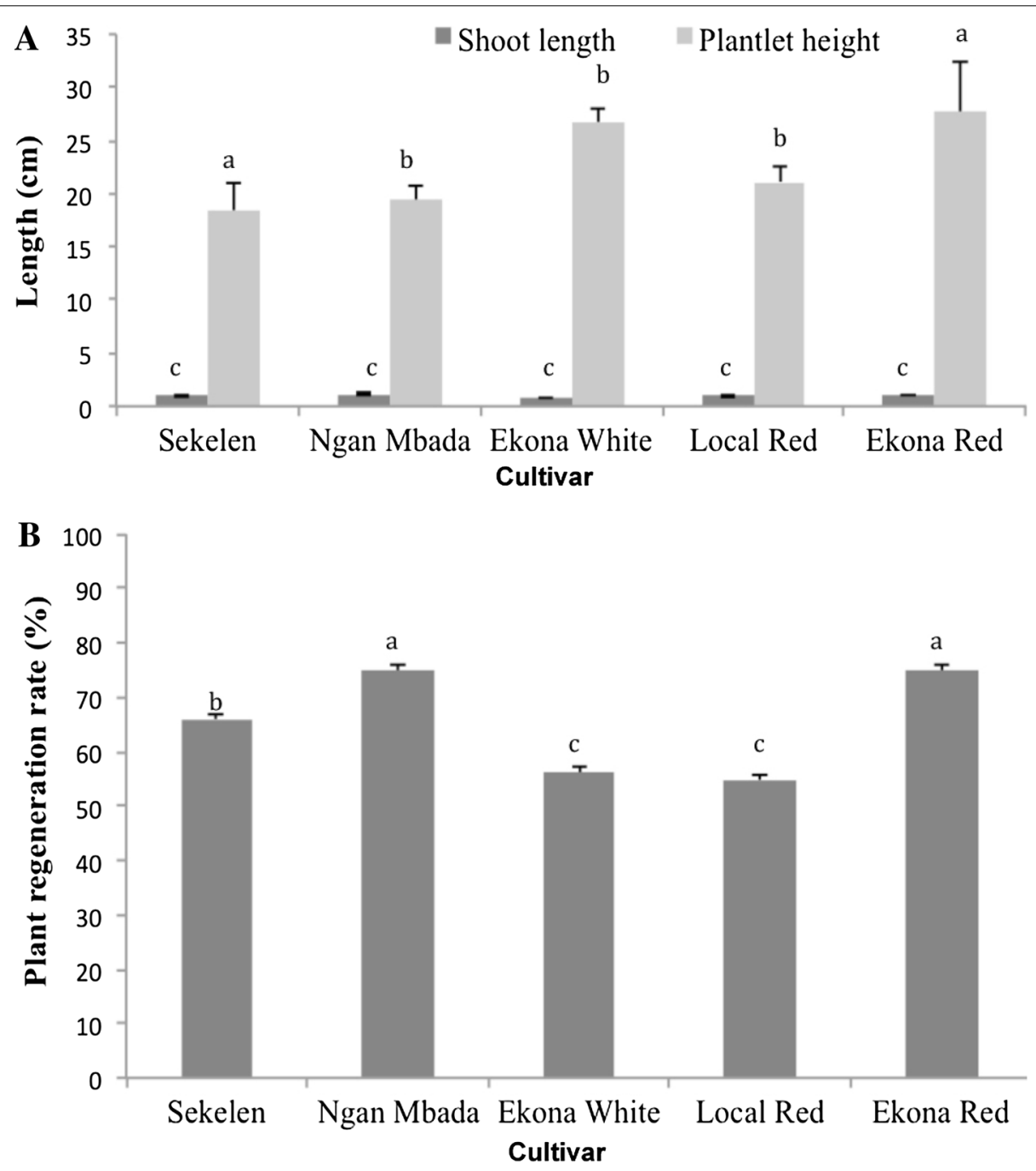

Fig. 4 Shoot bud length on organogenesis medium, acclimatized plants height (A) and establishment of plants in the greenhouse (B). Different letters on error bars are significantly different at $\alpha=0.05$ (Newman-Keuls test)

produced varied in primary and secondary embryogenesis, consistent with previous reports (Saelim et al. 2006; Sofiari et al. 1997). Furthermore, green secondary embryo explants were observed to produce more somatic embryos than isolated shoot apexes and would likely be excellent targets for genetic transformation. Cyclic embryogenesis appeared to affect the number of somatic embryos produced than the frequency. It is possible that loss of competence to convert proembryogenic masses to different developmental stages declines with successive embryo cycles, starting from the fourth cycle.

This study showed the inability of NAA to induce formation of primary somatic embryos from meristem leaf lobe explants even though it induced production of secondary somatic embryos from primary somatic embryos. This result is in agreement with results from others
(Guohua and Qiusheng 2002; Sofiari et al. 1997; Raemakers et al. 1995). The efficiency of induction of secondary embryogenesis by $2,4-\mathrm{D}$, and especially NAA, varied considerably amongst all five cultivars assessed, thus, contrast with those of Sofiari et al. (1997), who reported that NAA was more proficient in inducing secondary embryogenesis than 2,4-D. We further found that NAA supplemented medium was more efficient at induction and maturation of secondary embryos compared with medium supplemented with Pic or 2,4-D. Indeed, production of green cotyledons from embryos took only 10 days on NAA medium whereas 3-4 weeks were required for Pic and 2,4-D. Thus, the whole embryogenic cycle using secondary somatic embryos can be completed in 14 days on NAA compared with at least 30 days for Pic or 2,4-D. Therefore, depending on the genotype, 
NAA is a plausible regeneration supplement since time is an important limiting factor in cassava regeneration.

Organogenesis from cotyledons of maturing somatic embryos is the most commonly used regeneration method for cassava (Fregene and Puonti-Kaerlas 2002). In contrast to the medium supplemented TDZ, callus induction was observed on the medium containing BAP. It is obvious that the auxin IBA combined with BAP might be responsible for this callus induction. Our results showed that BAP treatment gave the best organogenesis responses and thus in agreement with others (Guohua and Qiusheng 2002; Hankoua et al. 2005). It is not clear why TDZ was less efficient in inducing organogenesis from maturing somatic embryos, it is possible that the concentration may be an important factor and subsequent studies will need to assess different levels.

Although the frequency of bud induction was found in this study to be similar under light and dark conditions, the numbers of buds formed per explant were significantly higher when green cotyledons were incubated under $16 \mathrm{~h}$ light. The photoperiod has consistently been shown to be genotype-dependent for shoot formation. For example, a photoperiod of $16 \mathrm{~h}$ light was reported to be more efficient in inducing shoot formation from green cotyledons (Hankoua et al. 2005), while Li et al. (1998) obtained better results under continuous dark. We found that cv. Ngan Mbada was efficient in embryogenesis but less proficient in organogenesis, suggesting that the ability to produce somatic embryos does not necessarily translate to shoot regeneration proficiency. This result indicates that somatic embryogenesis and organogenesis may be controlled by different and independently inherited traits.

Taken together, this study shows that the Cameroon cultivars investigated here contain sufficient genetic variability for somatic embryogenesis and adventitious shoot formation and can likely be improved using the Agrobacterium-mediated approach. It is important to indicate that whereas some cassava cultivars from Colombia (Szabados et al. 1987; Mathews et al. 1993), Argentina (Medina et al. 2003) and Côte d'Ivoire (Konan et al. 1994) exhibit regeneration efficiencies similar to those reported here, others showed very low efficiencies.

\section{Conclusion}

Factors that produced significant differences in T-DNA delivery and regeneration include plant genotype, explant source, embryo size, duration of pre-culture, inoculation and co-cultivation of Agrobacterium. The efficient whole plantlet regeneration protocol established here, allows for initiation of totipotent friable embryogenic callus, which is routinely used as target tissues for transgene insertion. Therefore, important traits such as resistance to cassava mosaic diseases, reduced toxic cyanogene content in tuberous roots, high protein content and drought tolerance can be introduced to these cultivars.

\section{Methods}

\section{Plant materials}

Seven farmer-preferred cassava cultivars from Cameroon were used in this study. Four of the cultivars are grown extensively in southwestern Cameroon, namely Ekona Red, Ekona White, Local Red, and Local Ama while three are grown in the north, Sekelen, Ya Oroup, Ngan Mbada. Plants were maintained by monthly subcultures of in vitro shoot cultures as described by Hankoua et al. (2005). The culture medium consisted of MS (Murashige and Skoog 1962) basal medium containing $20 \mathrm{~g} / \mathrm{L}$ sucrose, $2 \mu \mathrm{M} \mathrm{CuSO}_{4}$ (pH 5.7), $0.8 \%$ of Noble agar [cassava basal medium (CBM)]. The cultures were kept in a culture room at $25 \pm 2{ }^{\circ} \mathrm{C}$ under $16 \mathrm{~h}$ light and light intensity of $3000 \mathrm{~lx}$.

\section{Induction of somatic embryogenesis}

Apical meristem-immature leaf lobes (AM-ILL) were excised from in vitro plantlets and cultured on MS basal medium containing $20 \mathrm{~g} / \mathrm{L}$ sucrose, B5 vitamins (Gamborg et al. 1968), $2 \mu \mathrm{M}$ additional copper in the form of $\mathrm{CuSO}_{4}$ (Schopke et al. 1992) and supplemented with 33 or $50 \mu \mathrm{M}$ of auxins 2,4-Dichlorophenoxyacetic acid $(2,4$ D), Picloram (Pic), $\alpha$-Naphthalene acetic acid (NAA), and Dicamba (Dic), respectively. Embryonic structures were examined using a stereomicroscope. Primary somatic embryos clusters containing globular, torpedo and heart-shaped structures were divided into units of 5-10 embryos. To develop green cotyledonary embryos or "maturing somatic embryos", each cluster was transferred onto cassava maturation medium (CMML) (MS medium supplemented with $20 \mathrm{~g} / \mathrm{L}$ sucrose, and $0.1 \mathrm{mg} / \mathrm{L} \mathrm{BAP)}$ as described by Li et al. (1996).

To assess primary and secondary somatic embryogenesis, we used cultivars Sekelen, Ngan Mbada, Local White, Local Red and Ekona Red, which produced sufficient numbers of green cotyledonary somatic embryos for downstream experimentation. Green cotyledon pieces $\left(5 \mathrm{~mm}^{2}\right)$ were excised from the primary cotyledon embryos and transferred to P-CIM (callus induction medium supplemented with $50 \mu \mathrm{M}$ Pic). Secondary somatic embryos were induced from green cotyledons of primary somatic embryos on $50 \mu \mathrm{M}$ of Pic, NAA and 2,4-D, respectively. Induced secondary somatic embryos were then divided into small clusters of 5-10 and transferred onto CMML for maturation. Green cotyledon pieces obtained from 2 week-old secondary cotyledon embryos were placed on CIM supplemented with $50 \mu \mathrm{M}$ Pic, NAA and 2,4-D for the induction of cyclic somatic embryogenesis. 
Somatic embryogenesis was carried out in a growth chamber set at $25 \pm 2{ }^{\circ} \mathrm{C}$ in continuous dark. Each treatment contained 10 Petri dishes and each Petri dish containing five explants (50 explants per treatment). The frequency of somatic embryogenesis and average number of somatic embryos produced at each stage per embryogenic callus were recorded from 3 to 4 weeks of culture.

\section{Effect of BAP and Thidiazuron (TDZ) on adventitious bud formation}

Thidiazuron (TDZ) is an active cytokinin-like substance routinely used as a regulator, including stimulation adventitious shoot formation in woody plant tissue culture. The cytokinin, 6-benzylaminopurine, benzyl adenine (BAP) also elicits plant growth and development responses. Thus, we assessed the effect of both regulators on adventitious bud formation of the cassava cultivars after three and four cycles of somatic embryogenesis. To do this, somatic embryos were divided into clusters of 5-10 embryos, which were transferred to CMML for maturation. Matured green cotyledon embryos were then divided into $0.5 \mathrm{~cm}^{2}$ pieces and transferred on cassava organogenesis medium (COM) [MS basal medium, vitamins $\mathrm{B} 5,20 \mathrm{~g} / \mathrm{L}$ sucrose and $2 \mu \mathrm{M} \mathrm{CuSO}_{4}$, supplemented with $1 \mathrm{mg} / \mathrm{L}$ BAP, $0.5 \mathrm{mg} / \mathrm{L}$ Indole butyric acid (IBA) or $0.022 \mathrm{mg} / \mathrm{L}$ TDZ, pH 5.7, and Noble agar (0.8 \%)]. Each treatment contained 10 explants in each of five Petri dishes (50 explants per treatment). Cultures were incubated either in continuous dark or fewer than $16 \mathrm{~h}$ light to determine the effect of light on bud formation. After 1 month in culture, the frequency of callus and bud induction, the number of buds per explant and shoot bud length were recorded.

\section{Elongation and rooting of shoot buds, and acclimatization of regenerated plantlets}

Shoot primordia from maturation medium were transferred onto cassava elongation medium (CEM: CBM supplemented with $0.4 \mathrm{mg} / \mathrm{L} \mathrm{BAP}$ ) for shoot elongation. After 4 weeks, the elongated shoots were transferred onto cassava rooting medium (CRM: CBM without plant growth regulators) for rooting and development. After root development, agar was rinsed from roots using tap water and the plantlets transferred to pots containing a Jiffy peat pellet. Pots were placed in closed transparent boxes to maintain high humidity and placed in the greenhouse where the temperature ranged from 18 to $25^{\circ} \mathrm{C}$ and the relative humidity from 80 to $60 \%$. After 10 days, boxes were opened slightly to allow air circulation and 1 week later, the cover was completely removed. The percentage of plantlet survival and their heights were recorded 4 weeks after being transferred to the greenhouse.

\section{Experimental design and statistical analysis}

All experiments were carried out in the completely randomized design. Samples were valuated using analysis of variance (ANOVA). Newman-Keuls multiple range tests were used to separate treatment means found significantly different by ANOVA. All analyses were at $\mathrm{P} \leq 0.05$ confidence level. Analysis was performed with the statistica 7.0 software.

\section{Abbreviations}

2,4-D: 2,4-Dichlorophenoxyacetic acid; BAP: benzylaminopurine; CBM: cassava basal medium; CEM: cassava elongation medium; CIM: callus induction medium; CMML: cassava maturation medium; COM: cassava organogenesis medium; CRM: cassava rooting medium; CSE: cyclic somatic embryogenesis; NAA: $\alpha$-Naphthalene acetic acid; P-CIM: callus induction medium supplemented with Pic; Pic: Picloram; PSE: primary somatic embryogenesis; SAM-ILL: shoot apical meristems immature leaf lobes; SE: somatic embryogenesis; SSE: secondary somatic embryogenesis; TDZ: Thidiazuron.

\section{Authors' contributions}

VNF conceived and designed the research. KM, OD and BK conducted the experiments. KM and VNF carried out the analysis. KM and VNF wrote the manuscript. All authors read and approved the final manuscript.

\section{Author details}

1 Department of Biological Sciences, Delaware State University, Dover, DE 19901, USA. ${ }^{2}$ Laboratory of Crop Breeding, Department of Natural Sciences, University Nangui Abrogoua, Abidjan, Côte D'Ivoire. ${ }^{3}$ Ekona Research Center, Institute of Agronomic Research for Development, Buea, South West Region, Cameroon.

\section{Acknowledgements}

This project was supported by NSF grant number IOS-1212576.

\section{Compliance with ethical guidelines}

\section{Competing interests}

The authors declare that they have no competing interests.

Received: 16 January 2015 Accepted: 25 August 2015

Published online: 04 September 2015

\section{References}

Atehnkeng J, Adetimirin VO, Ng SYC (2006) Exploring the African cassava (Manihot esculenta Crantz) germplasm for somatic embryogenic competence. Afr J Biotechnol 5:1324-1329

Barceloux DG (2009) Cyanogenic foods (cassava, fruit kernels, and cycad seeds). Dis Mon 55:336-352

Bull SE, Ndunguru J, Gruissem W, Beeching JR, Vanderschuren H (2011) Cassava constraints to production and the transfer of biotechnology to African laboratories. Plant Cell Rep 30:779-787

Ceballos H, Iglesias CA, Pereze JC, Dixon AGO (2004) Cassava breeding: opportunities and challenges. Plant Mol Biol 56:503-516

Ceballos H, Sanchez T, Morante N, Fregene M, Dufour D, Smith AM, Denyer K, Perez JC, Calle F, Mestres C (2007) Discovery of an amylose-free starch mutant in cassava (Manihot esculenta Crantz). J Agric Food Chem 55:7469-7476

Chávez AL, Sánchez T, Jaramillo G, Bedoya J, Echeverry J, Bolaños EA, Ceballos $\mathrm{H}$, Iglesias CA (2005) Variation of quality traits in cassava roots evaluated in landraces and improved clones. Euphytica 143:125-133

Danso KE, Ford-Lloyd BV (2002) Induction of high frequency somatic embryos in cassava for cryopreservation. Plant Cell Rep 21:226-236 
FAO (2008a) Cassava for food and energy security. FAO Media Centre, Rome. http://www.fao.org/newsroom/en/news/2008/1000899/index.html. Accessed July 2008

FAO (2008b) Faostat. FAO, Rome. http://faostat.fao.org/. Accessed July 2008

FAO (2012) Agricultural Statistics. Food and Agricultural Organization of the United Nations. Rome. http://faostat.fao.org. Accessed July 2008

Feitosa T, Bastos JLP, Ponte LFA, Jucá TL, Campos FAP (2007) Somatic embryogenesis in cassava genotypes from the northeast of Brazil. Braz Arch Biol Technol 50:201-206

Fregene M, Puonti-Kaerlas J (2002) Cassava biotechnology. In: Hillocks RJ, Thresh JM, Bellotti AC (eds) Cassava: biology, production and utilization. CAB International, Wallingford, Oxon, pp 179-207

Gamborg M, Miller RA, Ojima K (1968) Nutrient requirements of suspension cultures of soybean root cells. Exp Cell Biol Res 50:151-158

González AE, Schöpke C, Taylor N, Beachy RN, Fauquet CM (1998) Regeneration of transgenic cassava plants (Manihot esculenta Crantz) through Agrobacterium-mediated transformation of embryogenic suspension cultures. Plant Cell Rep 17:827-831

Guohua M, Qiusheng X (2002) Induction of somatic embryogenesis and adventitious shoots from immature leaves of cassava. Plant Cell Tiss Org 70:281-288

Hahn SK, Terry ER, Leuschner K (1980) Breeding cassava for resistance to cassava mosaic disease. Euphytica 29:673-683

Hankoua BB, Ng SYC, Fawole I, Puonti-Kaerlas J, Pillay M, Dixon AGO (2005) Regeneration of a wide range of African cassava genotypes via shoot organogenesis from cotyledons of maturing somatic embryos and conformity of the field-established regenerants. Plant Cell Tissue Organ Cult 82:221-231

Ibrahim A, Heredia F, Pinheiro C, Aragao F, Campos F (2008) Optimization of somatic embryogenesis, and selection regimes for particle bombardment of friable embryogenic callus and somatic cotyledons of cassava (Manihot esculenta Crantz). Afr J Biotechnol 7:2790-2797

Ihemere UE (2003) Somatic embryogenesis and transformation of cassava for enhanced starch production. PhD thesis, Ohio State University, Columbus, Ohio, USA

Konan NK, Sangwan RS, Sangwan-Norreel BS (1994) Efficient In vitro shootregeneration systems in cassava (Manihot esculenta Crantz). Plant Breed 113:227-236

Li H-Q, Sautter C, Potrykus I, Puonti-Kaerlas J (1996) Genetic transformation of cassava (Manihot esculenta Crantz). Nat Biotechnol 14:736-740

Li HQ, Huang YW, Liang CY, Guo JY, Liu HX, Potrykus I, Puonti-Kaerlas J (1998) Regeneration of cassava plants via shoot organogenesis. Plant Cell Rep 17:410-414

Liu J, Zheng Q, Ma Q, Gadidasu KK, Zhang P (2011) Cassava genetic transformation and its application in breeding. J Integr Plant Biol 53:552-569

Lobell DB, Burke MB, Tebaldi C, Mastrandrea MD, Falcon WP, Naylor RL (2008) Prioritizing climate change adaptation needs for food security in 2030. Science 319:607-610

Magalhães JS, Santos MDM, Cunha Filho FN, Blumer L, Guerra MP, Torres AC (2006) Indução de embriogênese somática em genótipos de batatadoce. Hortic Bras 24:79-83

Mathews H, Schopke C, Carcamo R, Chavarriaga P, Fauquet C, Beachy RN (1993) Improvement of somatic embryogenesis and plant recovery in cassava. Plant Cell Rep 12:328-333

Medina RD, Faloci MM, Solís Neffa V, Mroginski LA (2003) Embriogénesis somática y regeneración de plantas de mandioca (Manihot esculenta Crantz) de cultivares de interés para Argentina. Revista de Investigaciones Agropecuarias 32:143-160

Morante N, Sanchez T, Ceballos H, Calle F, Perez JC, Egesi C, Cuambe CF, Escobar D, Ortiz D, Chavez AL (2010) Tolerance to postharvest physiological deterioration in cassava roots. Crop Sci 50:1333-1338

Murashige T, Skoog F (1962) A revised medium for rapid growth and bioassays with tobacco tissue cultures. Physiol Plant 15:437-496

Nassar N, Ortiz R (2010) Breeding cassava to feed the poor. Sci Am 302:78-84

Ng SYC, Adeniyi OI (1994) Embryogenesis in African adapted cassava and evaluation of generates. The second international scientific meeting C.B.N (CBN II). August 22-26, p 56

Nweke FI, Spencer DSC, Lynam JK (2002) The cassava transformation: Africa's best-kept secret. Michigan University Press, East Lansing

Okogbenin E, Porto MCM, Egesi C, Mba C, Espinosa E, Santos LG, Ospina C, Marín J, Barrera E, Gutiérrez J, Ekanayake I, Iglesias C, Fregene MA (2007)
Marker-assisted introgression of resistance to cassava mosaic disease into Latin American germplasm for the genetic improvement of cassava in Africa. Crop Sci 47:1895-1904

Olsen KM, Schaal BA (1999) Evidence on the origin of cassava: phylogeography of Manihot esculenta. Proc Natl Acad Sci USA 96:5586-5591

Osorio M, Gámez E, Molina S, Infante D (2012) Evaluation of cassava plants generated by somatic embryogenesis at different stages of development using molecular markers. Electron J Biotechnol 15:3. doi:10.2225/ vol15-issue4-fulltext-3

Pinheiro MVM, Martins FB, da Cruz ACF, de Carvalho ACPP, Ventrella MC, Oton WC (2013) Maturation of Anthurium andraeanum cv. Eidibel somatic embryos from nodal segments. In Vitro Cell Dev Biol Plant 49:304-312

Raemakers CJJM, Amati M, Staritsky G, Jacobsen E, Visser RGF (1993) Cyclic somatic embryogenesis and plant regeneration in cassava. Ann Bot 71:289-294

Raemakers CJJM, Sofiari E, Kanju E, Jacobsen E, Visser RGF (1995) NAA-induced somatic embryogenesis in cassava. In: cassava Biotechnology Network: Proceedings of second international Scientific Meeting, Bogor, Indonesia. CIAT working document, vol 150, pp 355-63

Rossin CB, Rey MEC (2011) Effect of explant source and auxins on somatic embryogenesis of selected cassava (Manihot esculenta Crantz) cultivars. S Afr J Bot 77:59-65

Rudi N, Norton GW, Alwang J, Asumugha G (2010) Economic impact analysis of marker-assisted breeding for resistance to pests and post- harvest deterioration in cassava. Afr J Agric Res Econ 4:110-122

Saelim L, Phansiri S, Netrphan S, Suksangpanomrung M, Narangajavana J (2006) Optimization of In vitro cyclic somatic embryogenesis and regeneration of the Asian cultivars of cassava (Manihot esculenta Crantz) for genetic manipulation system. Glob J Biochem Biotechnol 1:7-15

Sayre R, Beeching JR, Cahoon EB, Egesi C, Fauquet C, Fellman J, Fregene M, Gruissem W, Mallowa S, Manary M (2011) The BioCassava plus program: biofortification of cassava for sub-Saharan Africa. Annu Rev Plant Biol 62:251-272

Schopke C, Chavarriaga P, Fauquet CM, Beachy RN (1992) Cassava tissue culture and transformation: improvement of culture media and the effect of different antibiotics on cassava. In: Roca WM, Thro AM (eds) Proceedings of the First International Scientific Meeting of the Cassava Biotechnology Network pp 140-145. 25-28 August 1992, Columbia

Sofiari E, Raemakers CJJM, Kanju E, Danso K, Van Lammeren AM, Jacobsen E, Visser RGF (1997) Comparison of NAA and 2,4-D induced somatic embryogenesis in cassava. Plant Cell Tissue Organ Cult 50:45-56

Szabados L, Hoyos R, Roca W (1987) In vitro somatic embryogenesis and plant regeneration in cassava. Plant Cell Rep 6:248-251

Taylor NJ, Clarke M, Henshaw GG (1993) The induction of somatic embryogenesis in fifteen African and one South American cultivars. In: Roca W, Thro AM (eds) Proceedings of the First International Scientific Meeting of the Cassava Biotechnology Network (Working Document No 123). CIAT, Cali, pp 137-139

Taylor NJ, Masona MV, Carcano R, Ho T, Schopke C, Fauquet CM (2001) Production of embryogenic tissues and regeneration of transgenic plants in cassava (Manihot esculenta Crantz). Euphytica 120:25-34

Taylor N, Chavarrriaga P, Raemakers K, Siritunga D, Zhang P (2004) Development of transgenic technologies in cassava. Plant Mol Biol 56:671-688

Vidal ÁM, Costa MAPDC, Souza ADS, Almeida WABD, Souza FVD (2014) In vitro regeneration and morphogenesis of somatic embryos of cassava. Revista Ciência Agronômica 45:558-565

Westby A (2002) Cassava utilization, storage and small-scale processing. In: Hillocks RJ, Thresh JM, Bellotti AC (eds) Cassava biology, production and utilization. CABI Publishing, Wallingford, pp 281-300

Zamora LL, Calderón JAG, Vázquez ET, Reynoso EB (2010) Optimization of ethanol production process from cassava starch by surface response. $J$ Mex Chem Soc 54:198-203

Zhang P, Puonti-Kaerlas J (2005) Regeneration of transgenic cassava from transformed embryogenic tissues. In: Peña L (ed) Transgenic plants: methods and protocols. Humana press Inc, New Jersey, pp 165-176

Zhang P, Phansiri S, Puonti-Kaerlas J (2001) Improvement of cassava organogenesis by the use of silver nitrate in vitro. Plant Cell Tissue Organ Cult 67:47-54 